two small clots, nothing was found in its cavity. Next day, the napkins being still largely stained with florid blood, I introduced an elastic catheter, with the opening at its point, into the uterus, and injected about half an ounce of aqueous solution of iron alum (strength two scruples to the ounce), which had the desired effect. In two days the injection had to be repeated, after which the bleeding gradually stopped. I had ceased attending for a week when she took a sudden flooding after washing her feet in hot water. The same means were employed as hitherto, and were attended with the same difficulty. After a course of iron and quinine she eventually recovered.

CASE 8.-Mrs. A-, aged twenty-eight, very anæmic. Eleven weeks previous to my visit had a mole abortion at third month. Had a living child the first year of her married life; had three consecutive abortions since, of which the mole was the last. This was preceded by much hæmorrhage, and at the time of visit (eleven weeks after) it had not ceased. The uterus was found somewhat retroflexed, and measuring three inches and a half, the os open, and its labia tumid. The uterin $\theta$ malposition was comparatively easily adjusted, though causing some pain. The organ apparentily contained no shreds of membrane nor clots, nor was the discharge fetid. She was advised to keep her bed, use cold astringent injections, take chiefly albuminous diet, also milk, wine, steel, and quinine. In about three days the bleeding completely ceased, and in a fortnight she was fairly convalescent.

Twelve months after she again became pregnant, of which I was duly apprised, and reiterated my advice to avoid phy. sical and mental excitement. She obtained my consent to reside a short time at the coast. A few weeks after she had to hurry to reach the boat. On arriving home she had slight hæmorrhage, shivering, felt sickly, also bearing-down pains, with backache. I found the os closed, but feared, from her abortive diathesis, another miscarriage. Stimulants were prohibited, a light diet ordered, with rest and quietness in the horizontal posture, and solution of opium with digitalis prescribed. This treatment seemed successful, and in a week I ceased visiting. In two days I was called, when the ovum entire was shown me. It contained a three months' embryo. Recovery was rapid, after which she resided some weeks at the seaside, having salt water baths daily, and taking compound syrup of phosphate of iron, with a regular allowance of light dry sherry.

In five months she was again pregnant. Being extremely anxious for offspring, and remembering previous experience, she put herself entirely under my care, and ultimately had a daughter at full term. Previous to her confinement there was much odema of the lower limbs, slight swelling of the features, and considerable albuminuria. These gradually disappeared under appropriate treatment after parturition. She made a good recovery, and is now in better bealth than for some years. Thc child, aged twelve months, is well. She is again five months pregnant.

CASE 9.-Mrs. J-, aged twenty-two, in third month, first abortion, first pregnancy, married four months. Two days before had been polishing a friend's table, the obvious cause of her illness. I found her much depressed and vomiting. There was little bleeding, but severe and frequent bearing-down pains. Theovum was projecting through the os. A dose of ergot was given. After an hour, no change taking place in her condition, I left. On my return in six hours I was shown the ovum entire, newly cast off. The hæmorrhage was trifling. Three days subsequently she had a slight attack of metritis, which jielded to subchloride of mercury and compound ipecacuanha powder, with hot applications to the abdomen, and washing out the vagina with water acidulated with $\mathrm{HCl}$; otherwise she made a good recovery.

CASE 10. - Mrs. M'C__, aged twenty-eight, in the fifth month, first abortion, fourth pregnancy. When in her fourth month she had an oozing of blood from the vagina, with bearing-down pains-the apparent result of a long walk. She was kept in bed a week, and sedatives administered successfully. Soon after she had severe acute bronchitis, causing prolonged paroxysms of coughing, for which she was kept in bed two weeks. When scarcely recovered, an only child had inflammatory diarrhœa, causing her much anxiety and extra trouble. After he got well she set to a day's cleaning, in direct opposition to my emphatic instructions and also those of her husband. The same night uterine contractions began. I found little hæmorrhage; the funis prolapsed and pulseless. The presentation was footling the lower half of the fotal body lay in the vagina; the upper was grasped by the uterus. Traction on the limbs with two fingers failed to disengage it. Ergot with borax had no effect. During the next twelve hours I saw her several times. Latterly the foetus was expelled. A large dose of ergot was given to assist in the expulsion of the placenta; the effect was again nil. On tracking the cord in the vagina, it was found entering the os, which only admitted the point of the finger. Causing an attendant to grasp the uterus over the pubes, I made slight traction on the cord with the right hand, and endeavoured with my left to dilate the os and otherwise assist in extracting the placenta; but the cord parted within the uterus. I tried to pass the hand into the vagina, but failed. There being still little bleeding, I resolved to wait and see what nature would do. Nature took matters easy. For two days she fed well, slept soundly, and was painless; but I was getting anxious. Chloroform was given, and with the left hand in the vagina and the right steadying the uterus over the pubes, I dilated the os to the size of a crown-piece, and found the placenta adhering to the left uterine wall and part of the fundus. The most extreme difficulty was experienced in getting it separated, the two fingers not being able to work at the fundus, nor the hand to enter the uterus; consequently, about two-thirds of it was extracted in small shreds. Latterly the adhesion was separated, and a good hold obtained of the remaining large part, which was liberated coincident with a uterine spasm. Five bours after the patient was flushed, and complained of headache; pulse 108. Next day the pulse was 72 ; headache gone. She recovered rapidly without a bad symptom.

CAST 11.-Mrs. C - aged twenty, in third month, first abortion, second pregnancy, after walking about seven miles, had bearing-down pains with profuse flooding. I found her supported by two persons and unable to move. She was put to bed, and as the pain was unusually severe, thirty minims of sedative solution of opinm were given. The os admitted the finger, and the foetal ovoid was found jammed in the cervix. $\Delta$ towel soaked in cold water was applied to the vulva, the pelvis raised, and the shoulders lowered. This lessened the hæmorrhage, while the opium soothed the pain. About three hours after her bowels inclined to move, she insisted on getting up, and fainted. On my arrival she was recovering, but blanched and nearly pulseless. Brandy had just been given, by which, with the horizontal posture, she revived. The membranes were now protruding, the hæmorrhage had ceased, and the pain was nearly gone. After waiting about an hour, and her condition remaining the same, ergot with borax was given, and, assisted by the two fingers grasping the membrane, resulted in the expulsion of the ovum entire. Patient made a fair recovery, and was pregnant four months after.

(To be concluded.)

\section{OPHTHALMIC MEMORANDA.}

BX EDGAR A. BROWNE,

SURGHON TO THE TYE AND EAR INEIRMARY AND THE DISPBNSARY FOR SKID DISHASES, LIVERPOOI,

1. A CASE of partial staphyloma corneæ afforded an opm portunity for trying a method of treatment which I do not remember to have seen previously employed.

C. S-, workman, St. Helens, having neglected a gonorrhcal ophthalmia of the right eye, was first seen when a large sloughing ulcer of the outer and lower third of the cornea was threatening perforation. Although the eye was rescued, a large staphyloma resulted. The protuberance was exceedingly unsightly, and gave rise to inconvenience by preventing closure of the lids. As useful vision upwards and inwards remained, the only ordinary method available seemed to be repeated paracentesis with pressure. But, considering how often this plan fails to do good even in small staphylomata, I resolved to imitate a process now in vogue for conical cornea, and operated (May $7 \mathrm{th}$ ) by transfixing the most prominent portion of the tumour with a Graefe's knife. The incision was an eighth of an inch long, 
parallel to the long axis of the swelling, and obliquely inclined to its surface. The flap was seized with the iris forceps, and a tiny wedge-shaped piece was snipped off by the scissors. Firm pressure was then applied. I felt very doubtful of the capacity of the degenerated tissue for healing, and was delighted to find that the posterior edges of the wound had, in twenty-four hours, healed as readily as healthy cornea. The wound having completely cicatrised, though but little flattening had resulted, I again (May 28th) excised a wedge-shaped piece of tissue, about an eighth of an inch long and a line across at its widest part. This healed readily, and produced a marked improvement. On June $18 \mathrm{lh}$ I excised a third piece with like favourable result. When cicatrisation was complete the staphyloma was considerably flattened (though not quite level with the normal surface of the globe), and the lids closed easily and comfortably.

The main points conducive to success seem to be, that the posterior edges of the wound should be in apposition, and that a large piece of tissue be not removed at one sitting. As the operation is nearly painless, it might be repeated a dozen times if necessary.

2. Wound of an ocular muscle without injury to the globe is necessarily a rare and curious accident. The following is the only case I have ever seen.

J. K -, iron-roller, St. Helens, was hit by a flying fragment of metal between the lower lid and the globe, neither of which, strange to say, was injured. He applied at the infirmary some weeks after the accident on account of vertical diplopia. On inspection, an upward squint was manifest, and the power of downward movement was considerably impaired. At the bottom of the retro-tarsal fold was an irregular cicatrix, and the lower part of the ocular conjunctiva was red and much thickened. On June 11th I operated by snipping a free horizontal opening in the conjunctiva, about an eighth of an inch from the corneal margin. The tissues were matted together, but by careful employment of scissors and hook the attachments to the globe were freed; the tendon remaining joined to the conjunctiva. The superior rectus was now divided, and the lower tendon brought forward by three silk sutures, which were drawn sufficiently tight to give the eyeball a slight downward inclination. The wound healed readily; but when the superior rectus regained its power the improvement was found to be only partial, and I therefore (August 6th) brought the inferior rectus still further forward by a second operation, but did not again divide the superior tendon. 'The pupil was at first half its diameter lower than its fellow, but after the withdrawal of the sutures it gradually rose till it was level. The patient was discharged cured.

Liverpool.

\section{ON THE TREATMENT OF ALVEOLAR ABSCESS.}

BY ISIDOR I. LYONS, M.R.C.S., L.D.S.

ALVEOLAR abscess is the result of an acute inflammation of the periodental membrane. This may arise from various causes. It is commonly the sequel of acute inflammation of the pulp of a tooth, but it may commence in the membrane. An alveolar abscess generally points opposite to the buccal or labial surface of the affected tooth, or the pus may exude at its neck or travel along the hard palate and open at any point internal to the dental arch.

Among the different local remedies prescribed for this affection, the most common are external fomentations and poultices. This treatment is to be deplored for the following reason. When, for example, an abscess takes place at the root of an upper bicuspid tooth, and the swelling is at its buccal surface, on a poultice being applied externally, pus would travel above the fold of mucous membrane connecting the superior maxilla with the cheek, and appear among the buccal muscles, ultimately passing throngh the skin, thereby producing those ugly scars often seen on the face of patients who have undergone this treatment. The following cases are typical of these results.

Isabella $B-$, aged twenty-eight, admitted into St. Bartholomew's Hospital April 1st, 1875, under the care of Mr. Callender. This patient had suffered great pain for a long time from a carious lower molar, at the roots of which there had been an abscess. This had been treated by external fomentations and lancing of the gum. When admitted into the hospital, there was a soft red spot with two or three openings over the middle of the lower jaw, on the right side, extending behind towards the angle and ramus, and slightly down to the neck. There was also inability to open the mouth except to a very slight degree. The first lower molar was reduced to a stump. Since admission, the swelling behind and below has increased, and apparently suppuration taken place. On April 9th the right lower molar (which was necrosed) and the fangs of the two other teeth were extracted. On the 16th the abscess appeared to be discharging through openings in front of it. As regards the rest of the history of this patient, an attack of erysipelas supervened, involving both sides of the face, and which was remarkable for its severity and high temperature. On June 16th she was discharged, her general condition much improved.

Emily C-, aged twenty-four, admitted as an outpatient of the hospital April 8th, 1875, under the care of Mr. Coleman. This patient had acute periodontitis of the first left upper molar in the previous March, and was ordered to apply poultices externally. Within a week the abscess burst. In April she came to the hospital to have the tooth extracted. At that time the scar extended from that part of the cheek opposite the zygomatic arch to midway between it and the angle of the mouth.

G.S-, aged twenty-one, admitted as an out-patient on March 21st, 1875, under the care of Mr. Coleman. This patient had suffered from acute periodontitis of a left lower molar for one month; and, an abscess supervening, it was treated by external fomentations and poultices. At present there is a fistulous opening in the cheek.

The appropriate treatment in the above cases would, no doubt, be the immediate extraction of the offending teeth; but if desirous of saving them, by internal fomentations (the patient to be desired to bathe his mouth frequently with water at as warm a temperature as possible), also by lancing the gums and the application of leeches, and, when an abscess has formed, by free incisions.

The cases given are types of a very large number of outpatients seen at the dental department of the hospital.

\section{g. dituror}

\section{HOSPITAL PRACTICE, BRITISH AND FOREIGN.}

Nulla autem est alia pro certo noscendi via, nisi quamplurimas et morborum et dissectionum historias, tum aliorum, tum proprias collectas habere, $e$ inter se comparare.-Morgagri De Sed. et Caus. MLorb., lib. iv. Procmium

\section{ST. THOMAS'S HOSPITAL.}

OASE OF HYDROPHOBIA.

(Under the care of Mr. SYDNEY JoNas.)

A PoINT of interest in the following case, for the notes of which we are indebted to Mr. H. P. Potter, house-surgeon, was the benefit derived from the inhalation of chloroform. Although the case unfortunately proved fatal, the chloroform gave considerable relief.

Henry W-, aged twelve, a very healthy boy, rather hot-tempered but not nervous, applied at the hospital on September 24th, at 1 P.M., suffering from symptoms of bydrophobia. He had had no previous illness. The boy stated that six weeks ago, whilst stroking a dog which was chained, the animal snapped, and caught bold of his right little finger, and he had to pull it forcibly out of its mouth. No one else was bitten. The dog was killed two days after, and was said to be suffering from rabies. The finger was simply bound up in rag for two days, when he came to the hospital, and poultices were ordered. The wound healed in about a fortnight. During the interval the boy was pretty well, but sometimes he was rather strange in his manner; never spoke of fear of hydrophobia. On the evening of the 19th September he was taken with rigors, and complained 